\title{
Sea-food poisoning caused by brevetoxins in New Zealand
}

\author{
Hitoshi IsHIDA and Kuniro TsuJI \\ 石田 均司, 辻＼cjkstart邦郎：ニュージーランドで発生した Brevetoxin で毒化した \\ 二枚貝による食中毒
}

\begin{abstract}
A new polyether marine toxin, brevetoxin $\mathrm{B}_{1}$, and known brevetoxin, $\mathrm{PbTx} \cdot 3$, were isolated from the New Zealand shellfish cockle, Austrovenus stutchburyi and brevetoxin $\mathrm{B}_{1}$ was elucidated by comparison of its spectral data with those of brevetoxins B and use of NMR techniques. $\mathrm{PbTx}-2$ and 3 were isolated from oyster, Crassostrea gigas, harvested in 1993 at Tiki Road, Coromandel Peninsula, and $\mathrm{PbTx}-3$ also isolated from oysters collected at Rangaunu Harbour in February 1994 and June 1995.
\end{abstract}

In December 1992, several cases of intoxication following ingestion of bivalves occurred in New Zealand ${ }^{1)}$. The patients were not lost, but complained of visual defect, tingling lips, aching joints, temporary paralysis of the lower limbs, diarrhea, drowsiness, headache, etc. and recovered within a few weeks. The symptom profile was similar to that found in ciguatera ${ }^{2)}$.

The official mouse test was the only available technique for the initial monitoring of shellfish samples. Whole shucked bodies of shells were lyophilized, ground and extracted twice with $80 \%$ methanol under reflux. The extract was partitioned between methylene chloride and water, and the methylene chloride-soluble portion was further partitioned between n-hexane and $80 \%$ methanol. The methanolic parts, obtained from cockle, Austrovenus stutchburyi collected near Whangarei in January 1993 and oyster, Crassostrea gigas, harvested in January 1993 at Tiki Road and at Rangaunu Harbour in February 1994 and June 1995, when injected into mice, induced irritability, followed by severe dyspnea, convulsion and then death within 2 hours due to respiratory paralysis ${ }^{3}$ and 4). In this communication, we describe the isolation and structure determination of polyether neurotoxins from the intoxicated shellfish ${ }^{3 b}$ and 4).

On the basis of the above result, the methanolic part $(30.4 \mathrm{~g})$ of Whangarei cockle $(80 \mathrm{~kg})$ was applied to a column on $\mathrm{SiO}_{2}$ to get fr-1, 2 and 3 . All fractions showed neurotoxicity. Further purification of fr- 3 by successive chromatography afforded a new neurotoxin and of fr- 1 a known toxin as described below.

Approximately $5.4 \mathrm{mg}$ of a new neurotoxin 1, named brevetoxin $\mathrm{B}_{1}\left(\mathrm{BTX}-\mathrm{B}_{1}\right)$ based on the structure, was obtained from fr-3 by chromatography on columns of $\mathrm{SiO}_{2}$, ODS, and LH-20, followed by reverse-phase HPLC on YMC ODS column ${ }^{3 b}$. Fr-1 was partitioned between nhexane and $80 \%$ methanol and the toxic fraction was chromatographed on $\mathrm{SiO}_{2}$, Sephadex LH-20 and Sep Pak $\mathrm{C}_{18}$, followed by HPLC on various reversed-phase columns ( $\mathrm{C} 8$ and $\mathrm{C} 18$ ) to obtain ca. $1.2 \mathrm{mg}$ of compound $\mathbf{2}^{5}$.

School of Pharmaceutical Science, University of Shizuoka, 52-1 Yada, Shizuoka 422-8526, Japan 
The methanolic fraction from Tiki Road oyster $(30 \mathrm{~kg})$ was chromatographed on a Sephadex LH-20 and ODS. The toxic fraction was further purified by HPLC on various reversed-phase columns (C8 and C18) to obtain ca. $120 \mu \mathrm{g}$ of 2 . The $100 \%$ methanol eluate was further purified by HPLC on reversed-phase columns and on a normal-phase column $\left(\mathrm{SiO}_{2}\right)$ to obtain ca. $70 \mu \mathrm{g}$ of compound 3. Compound 2 (ca. $70 \mu \mathrm{g}$ ) was also isolated from Rangaunu Harbour oyster (10 kg) both in February 1994 and June 1995 by reference to the above procedure ${ }^{4)}$.

All data (mass, IR, NMR, UV and CD) allowed us to assign the structure of BTX- $\mathrm{B}_{1}$ to be 1 , with the molecular formula $\mathrm{C}_{52} \mathrm{H}_{74} \mathrm{O}_{17} \mathrm{NSNa}^{3 \mathrm{~b}}$. The minimum lethal dose of BTX- $\mathrm{B}_{1}$ thus isolated is $0.05 \mathrm{mg} / \mathrm{kg}$ (i. p.) in mice. Compounds 2 and 3 were identified as $\mathrm{PbTx}-3$ and 2 , respectively, by HPLC analyses and comparisons of their UV, mass and NMR spectra with those of the authentic samples ${ }^{4}$. Animals injected with the brevetoxins thus isolated exhibited irritability immediately after injection of, followed by hind and/or hind-quarter paralysis, severe dyspnea and convulsions prior to death due to respiratory paralysis; these symptoms are very similar to those caused by brevetoxins ${ }^{6}$. However, mice which did not develop respiratory difficulty recovered slowly.

Although it is well known that several brevetoxins, PbTx-1 to 7, are produced by the dinoflagellate Gymnodinium breve and along the Florida coast and in the Gulf of Mexico the red tide dinoflagellate $G$. breve is often responsible for massive fish and shellfish kills ${ }^{7}$, this is the first isolation of the brevetoxins $\mathrm{PbTx}-2$ and 3 and the analog from fish and shellfish ${ }^{3 \mathrm{~b}, 4)}$, to our knowledge.

It was recorded that between January and May, 1993, Gymnodinium sp. Nov. (cf breve) was the most abundant toxic dinoflagellate species off the north-east coast ${ }^{8}$. The oysters at Rangaunu Harbour, to the north of Tiki Road, are frequently contaminated with toxins, one of which is brevetoxin PbTx-3 as in case of Tiki Road oysters noted above. It appears that G. breve was one of the organisms responsible for the shellfish poisonings and human intoxications in 1993, and this organism is still present in Rangaunu Harbour in June 1995. Therefore, it is important to identify the Rangaunu Harbour organism to establish the source of the toxic phytoplankton involved in this food poisoning.

Interestingly, BTX- $\mathrm{B}_{1}$ at $100 \mathrm{ng} / \mathrm{ml}$ was not toxic to fresh water "zebra fish" (1.0-1.5 g) in one hour, unlike brevetoxin A (BTX-A), BTX-B and G. breve toxin-3 (GB-3) ${ }^{7}$.

Cockle contained mainly BTX- $\mathrm{B}_{1}$ and $\mathrm{PbTx}-3$, while toxic oysters did not contain $\mathrm{BTX}-\mathrm{B}_{1}$, but did contain mainly brevetoxin $\mathrm{PbTx}-3$ together with $\mathrm{PbTx}-2$. Recently new brevetoxin analogs named Brevetoxin $B_{2}$ and $B_{3}$, which are less ichthyotoxic as BTX- $B_{1}$, were isolated from greenshell mussels, Perna canaliculus, collected in 1993 in New Zealand ${ }^{9)}$. A new isolate of $G$. sp. in 1993 from the same region where the toxicated cockle or greenshell-mussle had been obtained implies that the less-ichthyotoxic brevetoxin analog such as BTX- $B_{1}, B_{2}$ or $B_{3}$ may be formed from brevetoxins such as BTX-B and GB-3 by the shellfish itself, and if so, ichthyotoxicity may not be a good guide to detect brevetoxin analogs in the shellfish and it would be interesting to know why $\mathrm{PbTx}-2$ and 3 existed in the oysters. It will be necessary to study the metabolism of brevetoxin in each shellfish for preventing food poisoning.

In conclusion, it is clear that brevetoxins participated as causative substances of the 1993 
New Zealand shellfish poisoning outbreak, based on the above results. It is likely that Gymnodinium species produced the toxins that accumulated directly or after metabolized in the shellfish.

\section{References}

1) Bates, M., Baker, M., Wilson, N., Lane, L., and Handford, S., The Royal Society of New Zealand Miscellaneous Series, 24, 35-40 (1993).

2) Halstead, B. W.: "Poisonous and Venomous Marine Animals of the Worlad", Vol. 2 (1967), U. S. Government Office, Washington, D. C.

3) a) Ishida, H., Nozawa, A., Nukaya, H., Tsuji, K., Kaspar, H., Berkett, N. and Kosuge, T., Toxicon, 32, 1672 -1674 (1994). b) Ishida, H., Nozawa, A., Totoribe, K., Muramatsu, N., Nukaya, H., Tsuji, K., Yamaguchi, K., Yasumoto, T., Kaspar, H., Berkett, N. and Kosuge, T., Tetrahedron Letters, 36, 725-728 (1995).

4) Ishida, H., Muramatsu, N., ,Nukaya, H., Kosuge T., and Tsuji, T., Toxicon, 34, 1050-1053 (1996).

5) Ishida, H., Muramatsu, N., Nukaya, H., Kosuge T., and Tsuji, T., Toxicon, in preparation.

6) Baden, D. G., FASEB J., 3, 1807-1817 (1989).

7) Golic, J., James, J. C., Nakanishi, K., and Lin, Y. Y., Tetrahedron Letters, 23, 25352538 (1982); Chou, H. N., and Shimizu, Y., Tetrahedron Letters, 23, 5521-5524 (1982) ; Chou, H. N., Shimizu, Y., Duyne, G. V., and Clardy, J., Tetrahedron Letters, 26, 2865-2868 (1985), Shimizu, Y., Chou, H. N., Bando, H., Duyne, G. V., and Clardy, J. C., J. Am. Chem. Soc., 108, 514-515 (1986).

8) Mackenzie, L., Rhodes, L., Till, D., Chang, F. H., Kaspar, H., Haywood, A., Kaspar, J. and Walker, B., "Harmful Marine Algal Blooms", pp. 795-800, Lavoisier Science Publisher, Paris (1995).

9) Satake, M., Morohashi, A., Murata, K., Kaspar, H. and Yasumoto, T., Tetrahedron Letters, 36, 8995-8998 (1995). 